\title{
ECONOMÍA MORAL Y ESTALLIDO SOCIAL: NO SON 30 PESOS, SON 30 AÑOS. LA CRISIS DEL NEOLIBERALISMO EN CHILE.
}

\author{
JOSÉ MIGUEL URZÚA* \& MATÍAS CALDERÓN**
}

\section{Introducción}

En realidad, la mera existencia de privaciones no es bastante para provocar una insurrección; de lo contrario, las masas siempre habrían estado en agitación.

(Trotsky citado en Brinton, 1962, p. 50)

El fenómeno social iniciado el viernes 18 de octubre de 2019 en Santiago y que se extendió por todo el país -llamado de otras maneras, como Estallido social en Chile, Chile despertó o Revolución de los 30 pesos-, tiene una relevancia analítica y política sinigual. No solo en este país, sino que de carácter global. Chile había sido uno de los principales ejemplos presentados para demostrar la imposición satisfactoria de las políticas liberales monetaristas o neoliberales ${ }^{1}$ en países pobres, del llamado tercer mundo, que poseían fuertes partidos políticos y movimientos sindicales, de raigambre marxista, socialdemócrata y socialcristiana, con presencia robusta dentro de la clase obrera y sectores medios.

El "milagro económico" chileno fue la rotulación que utilizó Friedman para caracterizar los efectos de la reducción del gasto fiscal y de la implementación del sistema social de mercado, por parte de los economistas asesores de la Dictadura cívico-militar durante 1975, en provecho de la disminución de la inflación, atribuida a políticas económicas keynesianas y socialistas (Friedmann en Bellolio, 2012).

El influyente periódico El Mercurio, cercano a la dictadura y afín al proyecto neoliberal, divulgó durante la década de 1990, la expresión "Chile es el jaguar de América Latina". Así, se enaltecían las transformaciones económicas consumadas por la dictadura, efectuando un paralelo con los denominados 'tigres asiáticos' (Corea del Sur, Taiwán, Singapur y Hong Kong) ${ }^{2}$. Los gobiernos posteriores a la dictadura, bajo el liderazgo de la coalición denominada Concertación de Partidos

\footnotetext{
* Programa de Antropología Jurídica, Universidad de Chile/Corporación Grupo de Investigación en Ciencias Sociales y Economí (GICSEC), Santiago, Chile. Correo de contacto: josemiguelurzuabravo@gmail.com

** Programa de Doctorado en Antropología Universidad Católica del Norte/Universidad de Tarapacá. Universidad Católica del Norte, San Pedro de Atacama, Chile/Corporación Grupo de Investigación en Ciencias Sociales y Economía (GICSEC), Santiago, Chile. Correo de contacto: mcalderonseguel@gmail.com
} 
por la Democracia, mantuvieron el modelo mediante profundizaciones y ajustes (Fazio \& Parada, 2010). En términos políticos, legitimaron con el manto democrático, el neoliberalismo que durante la dictadura habían cuestionado ${ }^{3}$. Las acotadas reformas que realizó la Concertación, fueron solo acciones reactivas a la presión de los movimientos sociales, especialmente el movimiento estudiantil en los años 2006 y 2011 (Paredes, 2019). Otras movilizaciones, como el movimiento mapuche, los levantamientos regionales asociados al centralismo y actividades extractivas, o por un cambio en el sistema de pensiones, no tuvieron la fuerza de impulsar ajustes relevantes al modelo.

En contraste con el optimismo de la elite, diversos estudios dan cuenta de la profunda desigualdad que forma parte del neoliberalismo chileno. Por ejemplo, al año 2017, el 50\% de los hogares con menores ingresos accedía a un $2,1 \%$ de la riqueza neta de Chile, el $10 \%$ más rico al $66,5 \%$, mientras que el exclusivo grupo del $1 \%$ más rico, concentraba el $26,5 \%$ (CEPAL, 2019). A su vez, también el 2017, del total de la población trabajadora del país, el 54,3\% obtiene un salario inferior a $\$ 350.000$ líquidos, el $74,3 \%$ consigue $\$ 500.000$ líquidos y solo el $16,1 \%$ alcanza $\$ 700.000$ líquidos o más (Durán \& Kremerman, 2019).

Entre la elite defensora y favorecida por el neoliberalismo, la crítica sobre la desigualdad es un tema de pulsiones y percepciones, además que destacan la reducción de la pobreza que ha ocurrido durante su existencia. De este modo, para ellos/as, Chile es el país que más ha reducido la desigualdad en América Latina durante los últimos veinte años y el malestar se debe a la impaciencia de la población por acceder a los beneficios materiales que proporciona el neolibe- ralismo (modelo que llaman de economía social de mercado) o también a la falta de conocimiento sobre cuanto a mejorado el ingreso gracias a esta economía (ver a Edwards en Matus, 2019). No obstante, Rodríguez (2016) demuestra que recién se está recobrando el índice de Gini de fines de la década de $1960^{4}$. A su vez, es verdad que los índices de pobreza han disminuido y las tasas de crecimiento han sido sostenidas, empero, Chile no ha podido reducir la desigualdad. Lo cual acontece por el empequeñecimiento del Estado, tributos regresivos que benefician a las grandes fortunas y focalización de ayudas monetarias hacia la población más vulnerable mediante ciertos requisitos estrictos (Repetto, 2016).

A contracorriente de las evidencias, el presidente de la República S. Piñera, días antes del estallido, sostuvo en el periódico financiero Financial Times ${ }^{5}$, que Chile era un "oasis" dentro de Sudamérica", pues estaba alejado de la contingencia de movilizaciones que sacudían la política interna de los países vecinos, originada por presiones ensalzadas por agrupaciones izquierdistas y populistas. Expresó que el país poseía una estabilidad interna devenida de un sólido sistema sociopolítico y de cifras satisfactorias en el ámbito macroeconómico, lo cual lo tenían abroquelado de la "amenaza populista". Durante ese mes y antes de las declaraciones de Piñera, se estableció un alza del transporte del tren subterráneo de la ciudad de Santiago (el Metro) en 30 pesos (0,04 US dólar, aproximadamente). Ante las movilizaciones de estudiantes secundarios en contra del alza durante el mes de octubre, la respuesta gubernamental fue negativa y ejerció represión policial para aplacarla, sin poder prever lo que emergería de tales acciones: las movilizaciones más grandes después del término de la 
dictadura y que, sin duda, ponían en duda los cimientes más profundos del neoliberalismo.

Conocer las motivaciones que originaron el estallido no es el propósito de este ensayo, pues tal empresa significa un estudio de mayor envergadura. Su intención es, más bien, explorar en la comprensión del estallido mediante el vínculo que existe entre moralidad y economía política ${ }^{7}$, a través del concepto de "economía moral” de E.P. Thompson (1995). Esta noción permite abordar los elementos culturales que se entretejieron con la estructura económica, a la vez que con las necesidades y precariedades inmediatas de las personas. Y que finalmente, legitimaron en la población las acciones de protesta, desborde del "orden público", la crítica a las instituciones y en última instancia, la deslegitimación explícita del neoliberalismo.

Para abordar lo expuesto, el ensayo fue organizado de la siguiente manera; primero, se presentará una revisión de los conceptos transformación social y economía moral, a partir de los autores más relevantes atinentes con los propósitos de este trabajo; posteriormente, identificamos otros momentos históricos en la historia de Chile en los cuales se produjeron revueltas populares a raíz de alzas en el transporte público; luego caracterizamos el estallido para analizarlo al vapor de las ideas de Thompson y culminamos con consideraciones finales.

\section{Transformación social y Economía moral}

A study of the moral economy of peasants can tell us what makes them angry and what is likely, other things being equal, to generate an explosive situation. But if anger born of exploitation were sufficient to spark a rebellion, most of the Third World (and not only the Third World) would be in flames (Scott, 1976: p. 4).
El estudio de las diferentes transformaciones sociales relacionadas a movilizaciones sociales, que han experimentado las agrupaciones humanas a lo largo del tiempo, es una tarea compleja. Explicar las razones, motivos o circunstancias que detonan revoluciones, estallidos, cambios o rebeliones en las sociedades por todo el globo, ha sido materia de investigación de las diferentes ciencias sociales, a partir de diversos enfoques, escuelas y teorías ${ }^{8}$, destacándose para los fines que persigue esta reflexión: Gramsci, Lukács, Scott y Thompson.

Gramsci es, sin duda, un autor cardinal para abordar la relación compleja entre materialidad e idealidad dentro de los procesos de legitimación y transformación de una sociedad determinada. Plantea que la revolución bolchevique fue una Revolución contra El capital de Marx (Gramsci, 2013a) en el sentido que, si el movimiento comunista ruso hubiese desarrollado la receta de la formación de una sociedad industrial burguesa como plataforma para el socialismo, la revolución no hubiese sido posible porque el país tenía estructuras económicas basadas principalmente en la agricultura, siendo el campesinado la clase mayoritaria. De esta manera, el italiano esgrime que los bolcheviques no renegaron del marxismo, sino que lo adaptaron a sus circunstancias y a las posibilidades de su voluntad, lo cual posiciona a la economía como un factor preponderante, pero no como una variable independiente de la cultura y la política.

A su vez, acuña el concepto de hegemonía para tratar los mecanismos culturales que permiten la dominación de clase (Gramsci, 2013b). Este permite rebasar las explicaciones meramente económicas, abordando la dialéctica entre consentimiento y sujeción, a 
partir de elementos culturales. Por medio de la hegemonía, las clases dominantes logran imponer su visión de mundo como sentido común, desde la educación, las creencias y la cultura en general. El proceso por el cual “... las ideas de la clase dominante son las ideas dominantes en cada época; o, dicho, en otros términos, la clase que ejerce el poder material dominante en la sociedad es, al mismo tiempo, su poder espiritual dominante" (Marx \& Engels, 1974: p. 50), es un transcurso complejo e implica para su consecución, la amenaza de coacción y el consentimiento de las clases sociales explotadas. Dentro este proceso, la intelectualidad juega un rol fundamental porque llevan al cabo el nexo de imposición desde los grupos dominantes a los subalternos.

Lukács (1970), asume la necesidad de recuperar la concepción de totalidad (pensamiento holístico de origen hegeliano), sobre todo, para abordar cuestiones de carácter no absolutamente material, como la conciencia de clase. Sostiene que la lucha política y la violencia esta mediada por las condiciones económicas y "momentos subjetivos". La separación de los componentes, favorece la fetichización de la economía como un ente aparentemente objetivo, desligando el papel principal de los sujetos en su ejecución, así como la mera invocación de la violencia sin entender el contexto productivo, desliga las reclamaciones de una sociedad compuesta por clases que pugnan por intereses, principalmente materiales. En cuanto a la conciencia de clase del proletariado, según el autor, no emergerá como un proceso natural y objetivo acontecido espontáneamente, que se manifestaría necesariamente como expresión nítida del papel revolucionario que posee. Incluso durante momentos álgidos, como las crisis capitalistas, la conciencia de clase puede situarse como una lucha particular cotidiana que no despliega la real condición del papel histórico de la clase trabajadora, lo cual demuestra que el proceso de toma de conciencia no es un producto mecánico forjado a raíz de la determinación de la base económica por sobre la superestructura ideológica.

Scott (2004), alejándose del marxismo (aunque inspirado en Thompson), estudia los actos de resistencia subrepticia de la población subordinada mediante el concepto infrapolítica. Este alude a "... una gran variedad de formas de resistencia muy discretas que recurren a formas indirectas de expresión" (Scott, 2004, p. 44) ${ }^{9}$. Con estos preceptos, enfatiza que no existan rebeliones abiertas de los grupos subalternos, no implica que estén de acuerdo con las ideas de las clases dominante y la sociedad respectiva. Estos planteamientos, en cierta forma, pondrían en duda el concepto gramsciano de hegemonía, ya que los grupos subordinados para Scott (2004), con aptitud perspicaz, alteran o abniegan de las de estas ideas según les parece, y no siempre de manera abierta y pública $^{10}$. Lo planteado por este autor puede ser útil para explicar los momentos -quizás mayoritarios- de "orden social", pero no las circunstancias de estallido o revuelta, que serían aquellos espacios de tiempo donde las "resistencias cotidianas", transitan a una resistencia abierta.

Thompson, el autor que inspira este ensayo, es uno de los representantes más importante de los estudios culturales, denominación que se le dio al conjunto de intelectuales británicos marxistas, influenciados por Gramsci, que estudiaron la situación de su región a partir de una concepción no determinante de la economía sobre los procesos sociales, siendo 
figuras señeras Hoggart, Williams, Hall y el mismo Thompson (Urteaga, 2009).

El historiador británico, a partir de la acuñación del concepto de economía moral, describe las revueltas durante el $\mathrm{s}$. XVIII en Inglaterra. Dichas revueltas fueron una demostración del ejercicio explícito de la multitud, que surgieron a partir del aumento excesivo y arbitrario de los precios del pan o por hambre, a través de una percepción popular referida a que dichas prácticas eran ilegítimas: "Esto estaba a su vez basado en una visión tradicional consecuente de las normas y obligaciones sociales, de las funciones económicas propias de los distintos sectores dentro de la comunidad que, tomadas en conjunto, puede decirse que constituyen la economía moral de los pobres" (1995, p. 216). El ultraje a estos principios morales, provocó la subversión del orden a través de una práctica política activa que se opuso a los principios nuevos del libremercadismo, que acabó con el paternalismo anterior que fijaba los precios y regulaba el mercado (Fig. 1).

Fig. 1 Elementos que componen la economía moral inglesa del s. XVIII

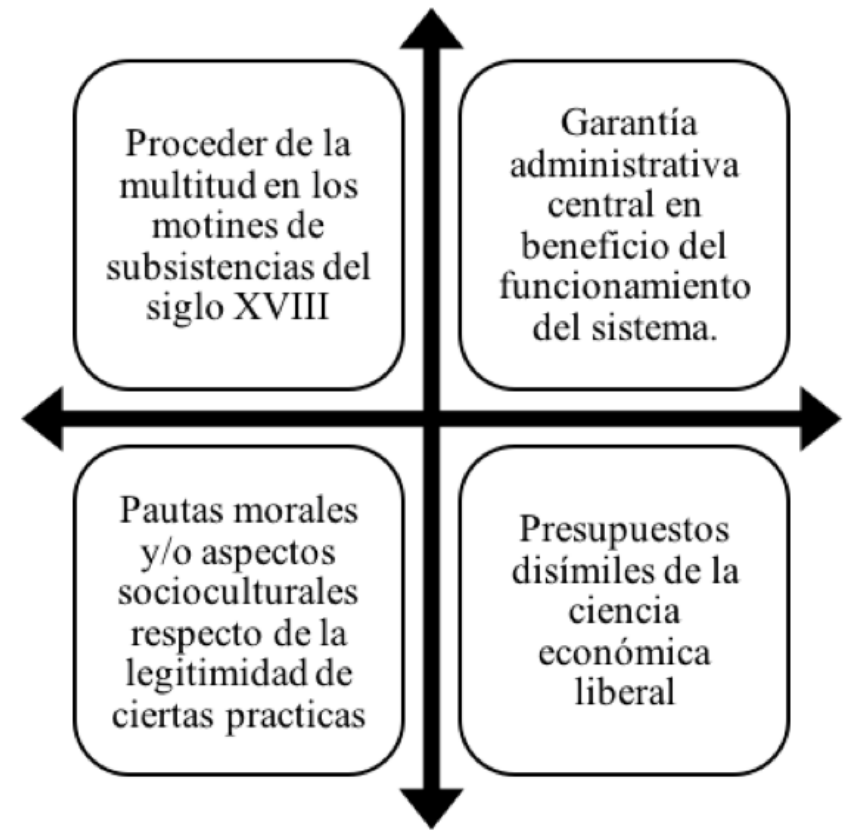

Fuente: elaboración propia.

Su proceder metodológico se basó en la caracterización del modelo paternalista de la comercialización de los alimentos, el cual constaba las medidas protectoras en períodos de carestía, provenientes de las épocas eduardianas y tudor, con el interés de contrastarlo con las ideas y medidas económicas impuestas a partir de las ideas que planteaban una relación armoniosa entre oferta y demanda aparecidas en La riqueza de las naciones de Smith, y establecer cómo en periodos de altos costes de las mercancías de primera necesidad, el 
comportamiento popular podía sobrevenir en acciones directa para controlar precios, invocando la licitud de las medidas económicas del modelo paternalista precedente.

Sin duda, la propuesta de Thompson no indica la conexión inmediata entre hambre-precariedad y revueltas sociales, ya que no se ejecuta como una relación automática y determinada por la carestía. Incluye como ejemplo, situaciones en las cuales existieron grandes carencias de bienes y servicios para solventar las necesidades básicas de los sujetos, pero que no sobrevinieron en revueltas o motines. Para el autor, el motín es una respuesta racional ejecutada por una agrupación humana que considera la posibilidad de apoyo mutuo a raíz de la existencia de una mínima cantidad de poder para enfrentar las alzas, la cesantía o la carencia de alimentos.

Por último, es importante establecer que Thompson no lleva a cabo una revisión elogiosa del proteccionismo paternalista precapitalista de precios a modo nostálgico, en detrimento de las ideas de un "caníbal" Adam Smith (p. 320). Su minucioso análisis histórico, critica tanto la "forma del capitalista clásico avaricioso o bajo la del hombre económico rebelde de la tradición marxista ortodoxa" (Thompson, 1995, p. 28). Su objetivo político, es la nueva búsqueda en el pasado de una "conciencia consuetudinaria», con el propósito de proyectarla en el futuro, en beneficio de la síntesis entre la satisfacción material equitativamente repartida y las expectaciones culturales respecto de la legitimidad de un sistema económico justo ${ }^{11}$.

\section{Otros levantamientos sociales asociados al transporte en Santiago de Chile}

¿Es justo que este estado de cosas continúe eternamente? Claro que no. ¿Cómo cambiar este orden de cosas basado en la inmoralidad?

(Recabarren, 1905, p. 141).

El propósito de este acápite es describir y rememorar otros acontecimientos en la historia del país en los cuales ocurrieron revueltas a partir del aumento de la tarifa de la locomoción colectiva, ejercitando así, el horizonte propuesto por Thompson relativo a la conformación de una "conciencia consuetudinaria» con base en la reconstrucción de la memoria y la acción práctica.

\section{La huelga de los tranvías}

El primer acontecimiento descrito es $\mathrm{La}$ huelga de los tranvías, ocurrido el 29 de abril de 1888 , cuando 2000 personas se agruparon y rechazaron el aumento del importe de segunda clase mediante la destrucción de varios de los vagones, convirtiendo una manifestación cívica, en una revuelta popular desde el centro a las barriadas populares que ocasionó destrucción del patrimonio estatal y privado.

Según la transcripción de la declaración de Antonio Poupin, máximo dirigente del Partido Democrático $^{12}$, hecha por Grez (1999), el movimiento pedía, mediante la mediación de la Municipalidad de Santiago, a la Empresa del Ferrocarril Urbano, construir más vías o bajar a dos centavos y medio el coste del transporte: “... supe que el pueblo había volcado y prendido fuego a varios carritos, ocurriéndoseme que se referían a los dos de que antes había hablado. 
Ignoro quiénes puedan haber azuzado al pueblo, lanzándolo en estos desórdenes y graves delitos expresados" (p. 160).

Grez (2000), haciendo un continuo entre la huelga de los tranvías y la huelga de la carne (ocurrida en 1905 por la subida de impuestos), expone que son una nítida demostración de la distancia entre grupos organizados y jerarquizados bajo una plataforma programática común y las masas espontaneas y sin mayor articulación, parafraseando a Hobsbawm (1983), "rebeldías primitivas". En ese sentido, podríamos incluso hallar una cierta vinculación con el estallido de 2019, en el sentido, que no existió una organización política centralizada y jerárquica con un petitorio pensado previamente y articulado a un plan de acción.

\section{La revolución de la chaucha}

El segundo acontecimiento histórico importante a destacar respecto el alza de la tarifa, es La revolución de la chaucha, acaecida el 16 y 17 de agosto de 1949 debido al aumento de 20 centavos de peso ("chaucha") en Santiago.

Durante una semana, la capital se vio envuelta en duros enfrentamientos entre la policía y la muchedumbre que arrasó con propiedad pública y privada, a raíz de un aumento significativo de la tarifa y que decantaron en la aprobación de Facultades Extraordinarias en el Congreso y una dura reprimenda a los participantes en las manifestaciones.

La crisis económica de postguerra, la presión de los dos bandos beligerantes durante la Guerra Fría, la inflación galopante, el bajo precio del cobre, el aumento del precio del crudo, la promulgación de la ley de defensa permanente de la democracia (1948) que ilegalizaba al Partido Comunista y la derechización del Presidente radical González Videla, fue el telón de fondo que contextualizó una de las revueltas más importantes sucedidas en la capital, incitada en un comienzo por estudiantes y reprimida por militares, aviadores y policías.

Según la prensa de época proclive al gobierno, fue una movilización urdida desde la clandestinidad por el Partido Comunista. Según Palma (2005), fue una manifestación espontánea de una multiplicidad de actores descontentos de la situación económica y política del país. Echeverría (2013) postula que otros grupos de izquierda no comunista, entre ellos el futuro fundador del Movimiento de Izquierda Revolucionaria (MIR) y dirigente sindical histórico Clotario Blest, fueron los instigadores y dirigentes del movimiento contestatario.

\section{La batalla de Santiago}

El tercer acontecimiento relacionado a las temáticas que este ensayo interpela es la Batalla de Santiago, conjunto de acontecimientos ligados al descontento popular acontecido en abril de 1957, en Santiago y otras ciudades, que precipitó la salida de los militares a la calle para reprimir las protestas.

La Batalla de Santiago ocurrió durante el segundo periodo presidencial de Carlos Ibáñez del Campo (1952-1958), a raíz de medidas de raigambre liberal promovidas por la misión Klein-Sacks para frenar la crisis económica que afectaba al país. Dicho grupo de expertos estadounidenses, le recomendó a Ibáñez el congelamiento de los salarios y la liberaliza- 
ción de precios, medidas que estaban en una posición diametralmente opuesta al keynesianismo estatista dominante en la época.

Dentro de este contexto, el aumento del importe del transporte público fue el detonante. La Central Única de Trabajadores llamó a la paralización de las actividades el 2 y 3 de abril. Unos días antes en Valparaíso, 30 de marzo, se produjeron barricadas y enfrentamientos entre carabineros y manifestantes (Milos, 2007).

La diferencia según Ljubetic (2004) entre Santiago y Valparaíso radicó fundamentalmente en la constitución de un Comando Contra las Alzas. En la ciudad porteña existió una dirección centralizada que se expresó en un comando que aglutinó y dio dirección a las masas. En el caso de Santiago, no existió por tanto fue más una explosión intuitiva de la muchedumbre que una acción planificada y dirigida con objetivos y acciones políticas prediseñadas. Al respecto, Romero (1957) y González (1957) en la Revista Principios nำ43, órgano de difusión del pensamiento del Partido Comunista, establecen argumentos del mismo talante, en el sentido que se alabó la acción de los comunistas porteños y se cuestionó el actuar de los militantes de la capital.

Las revueltas por el alza de la tarifa del transporte colectivo han sido, en momentos cruciales del país, un detonante clave para la implosión de conflictos de mayor extensión. En los tres casos presentados se vislumbra la relación entre la situación de desigualdades y la consideración de la población respecto de la injusticia relativa al aumento del precio de la movilización. En los diferentes episodios, se expresó la explosión de la muchedumbre que, raíz del acrecentamiento del valor del transporte, se enfrentó a la fuerza pública, la cual fue convocada junto a los militares para reprimirla. Por ende, no se aprecia la existencia de una manipulación o planificación previa para dirigir a la masa insurrecta desde algún partido o movimiento político.

\section{El estallido social por los 30 pesos}

¿Cómo se sostiene una democracia con una distribución tan injusta, que no cede si quiera a los esfuerzos que el Estado realiza en materia de política social? ¿cómo se sostiene sin rebeliones, sin protestas, sin una continua efervescencia social? (Moulian, 1997, p. 96)

Explicar las causas que originaron y desencadenaron el estallido son múltiples y no responden a un factor único. Previamente, hemos citado diferentes investigadores que hacen análisis críticos de variadas dimensiones de la desigualdad en el neoliberalismo chileno (Moulian, 1997; Mayol, 2012; Rodriguez, 2017; Cepal, 2019; Durán \& Kremmerman, 2019; Matus, 2019; Paúl, 2019). Considerar estos elementos es fundamental para comprender el estallido social, pero como se ha argumentado, no es suficiente. En un levantamiento como el del 18 de octubre de 2019 (y su prolongación por meses), solo encapsulado parcialmente por la pandemia del SARS-CoV-2, se conjugaron factores estructurales y situacionales que, por algún motivo, en ese momento se hicieron intolerables.

En este caso, corresponden a aspectos heterogéneos que engendraron descontento social, como son: a) las grandes brechas en la distribución de los ingresos, b) la corrupción política, militar, policial y empresarial, c) la colusión de grandes conglomerados económicos para manipular precios respecto mercan- 
cías de primera necesidad, d) impunidad y opacidad para castigar los delitos cometidos por las élites, y e) derechos sociales mercantilizados y precarios para la mayor parte de la población, la cual accede a la mayoría de ellos en base a la deuda. Junto con ellos, existen algunos detonantes de carácter contextual, por ejemplo, el incumplimiento de la promesa de crecimiento económico en el segundo mandato de Piñera, el aumento de la cesantía y algunas declaraciones burlescas por parte de las autoridades políticas frente a carencias de la población ${ }^{13}$.

Días antes de la publicación de estas declaraciones, agrupaciones de estudiantes secundarios, convocaron a una evasión masiva del ferrocarril eléctrico metropolitano debido al alza de 30 pesos en el pasaje durante el horario punta. La negación del gobierno a retrotraer el aumento y la invocación de la Ley de Seguridad Interior y el Estado de Emergencia, implicaron la emergencia de diferentes movilizaciones a lo largo de Chile mediante manifestaciones; incendios de las estaciones; saqueos e interrupciones de las vías de transporte de un amplio sector de la población. La movilización tiene su cénit el 25 de octubre con la concentración solo en Santiago de 1,2 millones de personas ${ }^{14}$, sin embargo, no ha perdido fuerza incluso en el período de vacaciones y que sólo se ha frenado por la expansión de la pandemia producida por el Covid-19.

Todos los elementos, tanto los estructurales como los de contexto, operaron engendrando descontento social, el cual se fue acumulando en distintas capas en la subjetividad de las personas. Algunos, los de mayor larga data, en sedimentos más profundos, mientras que los referentes a episodios presentes, se internalizan en niveles más inmediatos. El conjunto de los factores y episodios de descontento social, que en la experiencia cotidiana operan por carriles diferentes, se encontraron y sintetizaron el 18 de octubre de 2019, propulsando el estallido social. Si fuese un malestar pasajero o específico ${ }^{15}$, la ola de protestas y movilizaciones habría durado unos días o semanas, pero no varios meses. Las necesidades materiales y factores estructurales, se fundieron con experiencias cotidianas que se tradujeron en concepciones de una circunstancia injusta, una inmoralidad que genera tal indignación que provoca la eclosión social.

La subida del precio de los pasajes del Metro fue un aliciente fundamental para encender la mella que inició la crítica integral del sistema (González, 2020), fue el conector material y simbólico que articuló y luego sintetizó las diferentes capas de un descontento social acumulado por largos años. La segmentación de la ciudad de Santiago a partir de políticas públicas orientadas al libre mercado, generó la posibilidad de servicios precarios, entre ellos, el transporte para la clase trabajadora, que le aqueja en lo cotidiano. Esta situación nos conecta con las ideas de Thompson y Scott, en el sentido que la afectación tiene una relación a nivel del sujeto que debe sufrir esta desigualdad e injusticia de manera experiencial. Mayol (2019) ha planteado la existencia de un "desequilibrio normativo", gestado a lo largo de los años, a partir de diversas situaciones de abuso (con base en la desigualdad), como un elemento clave para entender la existencia del "estallido social". Pero para tratar de comprender que se haya producido justamente en el momento en que sucedió, es fundamental centrarse en el componente del transporte. 
El alza del pasaje del metro hizo explícito el cuestionamiento moral al orden neoliberal, gestado progresiva y subrepticiamente a lo largo de los años por distintos aspectos de desigualdad, abuso y humillación cotidiana que adquirían su forma más palpable en la condición del transporte público. Las condiciones del transporte configuraban una experiencia diaria que daba cuenta de la posición de clase -al margen de cómo se codificaba subjetivamente- que condensaba múltiples aspectos de la desigualdad del neoliberalismo chileno. Es por eso que el estallido ocurre en torno al transporte. En este sentido, el estallido propiamente tal, es el momento originario del tránsito entre el resquebrajamiento moral subrepticio hacia el cuestionamiento moral explícito que se ve en las movilizaciones desde el 18 de octubre. Los analistas neoliberales ven en la rápida adopción de consignas contra el modelo un indicador de "manipulación política", siendo que no son otra cosa que la cristalización de un cuestionamiento moral (y también económico-político) que se venía configurando en las masas de modo progresivo y relativamente silencioso.

Castillo (2019), en relación al rol del transporte público, señala que éste se tornó crecientemente esencial en la vida de las/os habitantes de Santiago, porque la clase trabajadora fue poblando, debido a la erradicaciones y precio del suelo, los sectores periféricos de la ciudad, y los viajes para trasladarse dentro de ella, por ende, se hicieron más extensos y tediosos, limitando así, el tiempo de divertimiento y participación con la familia.

Una de las principales demandas de los manifestantes ha sido la crítica a la amplia desigualdad producida por el neoliberalismo. La consigna central de la multitud movilizada ha sido: "no son 30 pesos son 30 años", para destacar que no solamente es un tema coyuntural de una determinada alza, sino una problemática decantada y asentada en la propia contextura del modelo de sociedad.

Las consignas del movimiento estudiantil que en un comienzo iniciaron las movilizaciones, fueron "evade como Piñera" y "evadir no pagar, otra forma de luchar", lo cual da una señal respecto de la configuración de la evasión como un aspecto transgresor dentro de un marco normativo injusto que actúa con opacidad frente a los delitos tributarios de la elite, pero que castiga con estrictez los delitos cometidos por personas sin privilegios, poder institucional e influencias.

La consigna "Hasta que la dignidad se haga costumbre", se ha vuelto un lema político-moral bastante extendido a partir de la detonación y desarrollo de estos acontecimientos. El epicentro de las manifestaciones, la plaza Baquedano, ha sido rebautizada por los/as manifestantes como Plaza Dignidad, en referencia al contenido de las protestas que consideran que el neoliberalismo les ha despojado de la cualidad decorosa mediante humillaciones e injusticias de todo tipo. Es interesante pues se establece de manera coloquial que Santiago está dividido entre dos sectores, por un lado, el sector oriente: alto, acomodado y rico, de predominancia de ascendientes europeos, y los sectores norponiente y sur: bajo, pobre y mestizo-indio, que tiene como hito fronterizo la rotonda mencionada. Es un elemento esencial en este movimiento, la instalación de la bandera mapuche en la plaza y diferentes esculturas para representar y dignificar a los pueblos indígenas de Chile y el carácter mestizo de la masa (foto 1). Es preciso sostener la presencia masiva de banderas mapuche, en contraposición a la existencia mínima de emblemas de partidos políticos. 
Foto 1. Tótems indígenas en Plaza Dignidad ${ }^{16}$

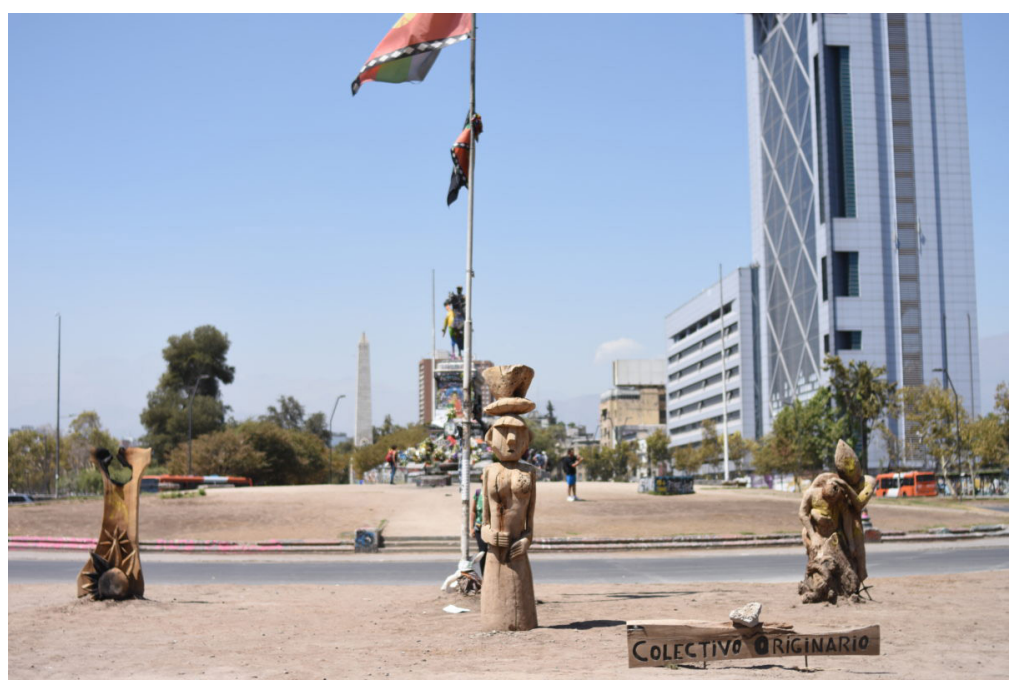

Foto: Valentina Manzano.

El estallido agudizó el cuestionamiento moral del modelo neoliberal mediante la disputa de sentido, dentro de un marco que desnudó el desequilibrio provocado por un sociedad fuertemente segregada y diferenciada que distribuye los ingresos, bienes, servicios y prestigio social de manera inequitativa. Según Mayol (2019), se puede trazar un paralelismo para comparar la quema de televisores por parte de manifestantes (foto 2) y el potlach, como mecanismo económico-cultural que poseen las diversas sociedades para distribuir la riqueza interna para mitigar y amortiguar posibles conflictos surgidos por la acumulación asimétrica (Barfield, 2001). Durante una protesta en octubre de 2019, en alameda con las rejas, Santiago norponiente, estaba aconteciendo una manifestación en la cual, un grupo procedió a saquear una tienda de retail (La Polar), involucrada en prácticas abusivas a los consumidores en 2010. Otro conjunto de personas que estaba haciendo una barricada, se dio cuenta de lo sucedido, y les arrebató los televisores a los saqueadores, para azuzar la hoguera que les ayudaba a interrumpir la calle. Es, sin duda, un acto que va más allá de un simple hecho delictual, en la medida que se puede hacer una lectura de deflagración simbólica de bienes que son el resultado de una acumulación asimétrica producida por un sistema injusto que no redistribuye los recursos de la sociedad de manera equitativa y que elige como presidente a una de las fortunas más grandes del país. Este es, sin duda, un acto económico-moral. 
Foto 2. ¿Por qué los manifestantes queman los televisores del retail en las barricadas? ${ }^{17}$

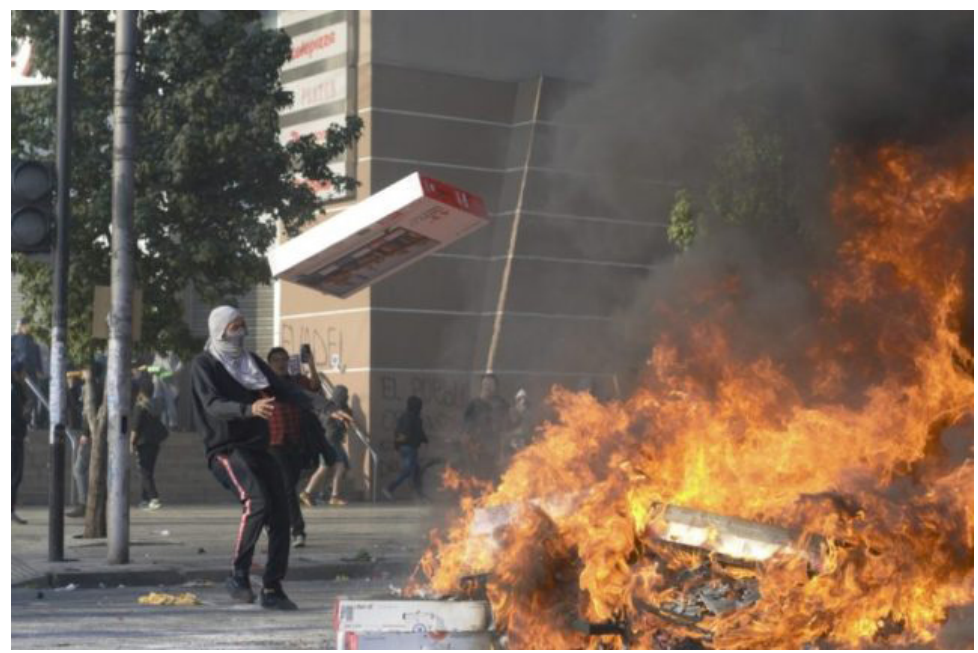

Foto: Alexander Carrizo

Las ideas y orientaciones de E.P. Thompson, pero también de Gramsci y Lukács en cuanto antecedentes de la articulación economía, política y cultura en el marxismo, son cruciales para explorar un entendimiento del estallido social y su complejidad, empero, estamos lejos de pretender haber llegado a su comprensión acabada, solo hemos delineado algunos compases iniciales en tal sentido. Otros elementos que no integramos en este análisis por espacio, pero que son centrales para la conexión economía-política y cultura durante el levantamiento iniciado el 18 de octubre, tiene que ver con la potencia del movimiento feminista ${ }^{18}$, la emergencia de diversos héroes populares (en un contexto de ausencia de referentes partidarios o políticos clásicos $)^{19}$, la destrucción e intervención de monumentos y esculturas asociados a la historia oficial ${ }^{20}$, la apropiación del espacio público mediante diversos murales, afiches y pinturas ${ }^{21}$, entre otros aspectos.
La invitación, por desafiante que resulte su puesta en práctica, es comprender a la realidad social como una totalidad, especialmente aquellos episodios donde, por diversas y variables causas, la población se alza en contra del orden establecido. La sociedad y sus dinámicas de cambio, se componen de elementos discordantes que se transmutan al impulso de sus propias refutaciones, de diferentes orígenes, económicos, políticos, históricos y culturales, tanto a nivel subjetivo, objetivo e intersubjetivo.

\section{Consideraciones finales}

Esta acepción directamente anticapitalista está cerca de la que introduje en La formación de la clase obrera en Inglaterra, cuando dije de los motines de subsistencias que eran «legitimados por las suposiciones de una economía moral más antigua, que enseñaba la inmoralidad de ... sacar provecho de las necesidades del pueblo» (Thompson, 1995, p. 380). 
El análisis de la manera en la cual la economía se entrelaza con otros aspectos del fenómeno humano, es evidente. Su separación es meramente una estrategia analítica, y si no se tiene consciencia de ello, ocurre por la fetichización de alguna de las esferas. Como hemos visto, una revuelta, motín o revolución son hechos complejos que abarcan varias dimensiones humanas. El estallido chileno de octubre no está alejado de aquello. Sin embargo, en este ensayo se hizo el hincapié en aspecto específicos.

Thompson es muy explícito en sostener que es imposible separar los dominios de la compresión de estos hechos, en la medida que están inextricablemente conectados. La disputa por la hegemonía es un factor clave para comprender las motivaciones que guían y dan sentido al accionar de los/as insurrectos/as. No es solo la precariedad material, ni tampoco el voluntarismo político y/o subversivo, es la dialéctica entre ambos elementos.

La inmoralidad en los cuatro casos histórico revisados fue subir el transporte público, referido explícitamente a un gasto cotidiano. De todas maneras, a lo largo de la historia de Chile, han ocurrido varias revueltas por diferentes alzas e injusticias sociales, sin embargo, es importante destacar que, en los cuatro casos expuesto, el detonante ha sido el aumento de la tarifa.

Antes de octubre de 2019, no era previsible el estallido, ni menos que iba a ser gatillado por dicha alza. Fue el descontento acumulado y originado por décadas de desigualdades que, en comunión con la identificación de una situación inmoral, presionó el percutor de la ira social de la multitud, que hizo saltar en pedazos la supuesta normalidad y conformidad alcanzada por los gobiernos garantes del orden neoliberal.

Establecer si las consecuencias de este estallido, será la vuelta al paternalismo proteccionista de un Estado de bienestar, es dificultoso de trazar en la actualidad. Sin embargo, es interesante esgrimir que es difícil que las condiciones estructurales e institucionales que cimentaron el modelo, no vayan a ser modificadas. Al momento de la escritura de este ensayo, estamos atravesando una situación sanitaria delicada debido al Covid-19, por lo que, las manifestaciones están en relativa calma, con brotes debido a la reclamación de ayuda por parte de pobladores/as al gobierno, la situación mapuche y casos emblemáticos de violencia patriarcal.

Para el 25 de octubre (2020) fue desplazado el plebiscito, que en un comienzo estaba planificado para abril, para votar sobre la mantención o cambio de la constitución, y los mecanismos para hacer una nueva (si triunfa la opción "apruebo"). Los cambios que se puedan realizar o no, estarán nuevamente en la palestra, en el sentido de si este nuevo modelo puede llevar a cabo la integración entre crecimiento económico y bienestar, mediante una riqueza justamente redistribuida y las expectativas morales de la población. No obstante, como formulara Marx, "las revoluciones son las locomotoras de la historia" (2015, p. 134), por tanto, creemos que es improbable que luego de lo ocurrido, se pueda desactivar o adormecer a un pueblo que despertó, desde la rabia e indignación y tomó conciencia, desde la sabiduría de su experiencia y sin necesidad de ningún manual, de la inmoralidad del orden neoliberal. 


\section{Notas}

${ }^{1}$ Corriente de pensamiento liberal basado principalmente en las ideas de Friedman y Von Hayek que aboga por un estado mínimo de carácter subsidiario y protector de la propiedad privada como derecho esencial.

2 Ver "La otra cara del 'jaguar' de América Latina" | Internacional Diario El País, 23/04/1998. http://elpais.com/diario/1998/03/23/ internacional/890607627_850215.html

${ }^{3}$ Un caso paradigmático fue Tironi (1988), quien escribió una crítica de uno de los primeros libros de apología del neoliberalismo chileno (Lavín, 1987). Tironi, saliendo de la dictadura, tuvo un radical cambio de opinión. Fue un exitoso asesor comunicacional empresarial y gubernamental en la época postdictadura. Sobre el tema ver Moulian (1997).

${ }^{4}$ Índice de 0,47 en 1969, el más bajo de la historia de Chile, pero con un PIB per cápita mucho menor.

${ }^{5}$ Ver "Chile president Sebastián Piñera: 'We are ready to do everything to not fall into populism'" https://www.ft.com/ content/980ec442-ee91-11e9-ad1e-4367d8281195.

${ }^{6}$ Ver Grupo de Investigación en Ciencias Sociales (2019) Oasis y levantamiento social. En www. https://rebelion.org/oasisy-levantamiento-social/

${ }^{7}$ Por moral se entiende el complejo de hábitos y pautas legitimadas, escritas y orales, para arbitrar, dirigir y promover un determinado comportamiento dentro de una agrupación humana (Gert, 2004) y por economía-política, el esquema global de extracción, producción, distribución, consumo y reciclaje/desecho de materias primas, mercancías y servicios (Laguna et. Al., 2015)

8 “... las soluciones propuestas por Marx y sus seguidores han tenido implicaciones revolucionarias; las de Weber o Parsons han tratado de apuntalar la cohesión social del entramado burocráticocapitalista, y las de Hobbes o Pareto han parecido proporcionar justificación para los regímenes autoritarios y totalitarios. No cabe duda de que la violencia es una categoría sociohistórica muy escurridiza, y que las diversas perspectivas de análisis no han sabido hasta ahora dar una explicación empíricamente verificable a todas sus posibles manifestaciones" (González Calleja, 2002, p.65).

${ }^{9}$ A partir del forjamiento de esta idea, el autor se acerca al planteamiento del llamado posestructuralismo. Revisar el concepto de «revolución molecular» (Rolnik \& Guattari, 2006).

10 "Cuando el gran señor pasa, el campesino sabio hace una gran reverencia y silenciosamente se echa un pedo" (Proverbio etíope citado en Scott, 2004, p. 9).

11 "Me parece que no es probable que esto suceda. Pero espero que los estudios que forman el presente libro iluminen de qué modo se forma la costumbre y qué complejo es su funcionamiento" (Thompson, 1995, 216).

${ }^{12}$ Agrupación política socioliberal constituida esencialmente por menestrales, trabajadores capacitados y letrados de capas medias separados del Partido Radical.
${ }^{13}$ Además de la calificación de "oasis sudamericano" de Piñera, el ministro de Economía (Juan Andrés Fontaine) señaló que quienes se levantaran más temprano accederían a tarifas más bajas en el metro (en una ciudad donde los tiempos de viaje son especialmente altos) o el llamado del ministro de Hacienda, ante el aumento general de los precios de primera necesidad, "a comprar flores" ya que era un ítem que había bajado en el IPC.

${ }^{14}$ Ver "Plaza Italia reúne 1,2 millones de personas y se convierte en la mayor marcha en 30 años". https://www.biobiochile.cl/noticias/ nacional/region-metropolitana/2019/10/25/comienzan-a-concentrarsemanifestantes-en-plaza-italia-para-la-marcha-mas-grande-de-chile. shtml

${ }^{15}$ Los intelectuales orgánicos del neoliberalismo, señalan que una insurrección de tal envergadura tiene por explicación un malestar juvenil o la incomprensión de la población de lo beneficioso que es en el fondo ( $y$ sin importar su experiencia de vida), este modelo. Las explicaciones más delirantes provinieron del propio gobierno, ante lo extendido del levantamiento social, mencionaron la existencia de una intervención extranjera rusa, venezolana, cubana, entre otros, y ejecutada por jóvenes seguidores de grupos del estilo de música K-pop (oriundo de Corea del Sur). Ver "“'Una rabia que se acompasa con el fulgor juvenil": La explicación de Carlos Peña para el caos" https://www.cooperativa.cl/noticias/pais/manifestaciones/ una-rabia-que-se-acompasa-con-el-fulgor-juvenil-la-explicacionde/2019-10-20/041006.html; "Luis Larraín: No son treinta pesos, son treinta años" https://ellibero.cl/opinion/luis-larrain-no-son-treintapesos-son-treinta-anos/; "Las hipótesis de la intervención extranjera en Chile" https://www.elmostrador.cl/noticias/opinion/2020/01/27/ las-hipotesis-de-la-intervencion-extranjera-en-chile/.

${ }^{16}$ Ver "Tótems indígenas en Plaza Dignidad: La lucha por la autonomía y reconocimiento de los pueblos originarios" https:// www.theclinic.cl/2020/02/07/totems-indigenas-en-plaza-dignidad-lalucha-por-la-autonomia-y-reconocimiento-de-los-pueblos-originarios/

17 Ver "¿Por qué los manifestantes queman los televisores del retail en las barricadas?" https://www.proyectoaurora.cl/index. php/2019/10/21/por-que-los-manifestantes-queman-los-televisoresdel-retail-en-las-barricadas/

${ }^{18}$ Ver "Las Tesis: de dónde viene "Un violador en tu camino" y cómo se convirtió en un fenómeno feminista mundial" https://www. bbc.com/mundo/noticias-50694888.

${ }^{19}$ Ver "Los héroes del estallido social en Chile" https://mundo. sputniknews.com/america-latina/201912161089664049-los-heroesdel-estallido-social-en-chile/

${ }^{20}$ Ver "Chile: destrucción de monumentos como protesta contra la historia oficial" https://www.dw.com/es/chile-destrucci\%C3\%B3nde-monumentos-como-protesta-contra-la-historia-oficial/a-51202577

${ }^{21}$ Ver "Los murales que deja el estallido social" https://amosantiago. cl/los-murales-que-deja-el-estallido-social/ 


\section{Referencias bibliográficas}

Barfield, T. (2001) Potlach. En Barfield, T. (Ed.), Diccionario de antropología (p. 504). Barcelona: Bellaterra

Bellolio, J. (2012). Recordando a Friedman: La libertad, la democracia y el progreso. En Soto, A. (Ed.), Un legado de libertad. Milton Friedman en Chile (pp. 85-93). Santiago: Instituto Democracia y Mercado/Atlas Economic Research Foundation/Fundación para el Progreso.

Brinton, C. (1962). Anatomía de la revolución. Madrid: Aguilar.

Castillo, S. (2019). La 'Huelga de la chaucha' reflejó muy bien el agotamiento de los santiaguinos. Interferencia. https://interferencia. cl/articulos/historiador-experto-la-huelga-de-la-chaucha-reflejo-muybien-el-agotamiento-de-los

CEPAL. (2019). Panorama Social de América Latina. Santiago: Comisión Económica para América Latina y el Caribe.

Durán, G. \& Kremerman, M. (2019). Los bajos salarios en Chile. Análisis de la encuesta CASEN 2017. Santiago: Fundación SOL.

Echeverría Yáñez, M. (2013). Antihistoria de un luchador. Clotario blest 1823-1990. Santiago: LOM.

Fazio, H. \& Parada, M. (2010). Veinte años de política económica de la Concertación. Santiago: LOM.

Gert, B. (2004). Moral. En Audi, R. (Ed.), Diccionario AKAL de filosofía (pp. 688-689). Madrid: AKAL.

González, M. (1957). Las luchas de abril y la provincia de Santiago. Principios, $N^{\circ} 43$, (pp. 15-16).

González Calleja, E. (2002). La violencia en la política. Perspectivas teóricas sobre el empleo deliberado de la fuerza en los conflictos de poder. Madrid: Consejo superior de investigaciones científicas.

González Martínez, G. (2020) Más que treinta años. Desigualdad espacial y transporte colectivo en Santiago. Revista Planeo № 42 Ciudades Rebeldes, enero 2020. Recuperado de http://revistaplaneo. cl/2020/01/08/mas-que-treinta-anos-desigualdad-espacial-ytransporte-colectivo-en-santiago/

Gramsci, A. (2013a). La revolución contra El capital de Marx. En Sacristán, M. (Ed.). Antología Antonio Gramsci (pp. 149-153). Madrid: AKAL.

(2013b). La formación de los intelectuales. En Sacristán, M. (Ed.). Antología Antonio Gramsci (pp. 347-354). Madrid: AKAL.

Grez Toso, S. (1999) Una mirada al movimiento popular desde dos asonadas callejeras (Santiago, 1888-1905). Cuadernos de historia 19, pp. 157-193.

(2000). Transición en las formas de lucha: motines peónales y huelgas obreras en chile (1891-1907). Historia (Santiago), 33, pp. 141-225. https://dx.doi.org/10.4067/S0717-71942000003300004

Hobsbawm, E. (1983). Rebeldes primitivos. Estudio sobre las formas arcaicas de los movimientos sociales en los siglos XIX y $X X$. Barcelona: Ariel.

Laguna, H., Riella, R., Giometti, B., Melazzi, G., Picos, G., Geymonat, J., Oyantçabal, G., Marrero, N. \& Narbondo, I. (2015) Economía política cartilla de formación. Montevideo: Universidad de la República extensión universitaria.

Lavín, J. (1987). La revolución silenciosa. Santiago: Zig-Zag.

Ljubetic Vargas, I. (2004). 2 y 3 de abril de 1957 - La "batalla de Santiago". Punto Final Edición 564. Recuperado de http://www. puntofinal.cl/564/batallasantiago.htm

Lukács, G. (1970). Historia y conciencia de clase. La Habana: Instituto del Libro.

Marx, C. (2015). Las luchas de clases en Francia de 1848 a 1850. Madrid: Fundación Federico Engels.

Marx, C. \& Engels, F. (1974). La ideología alemana Crítica de la novísima filosofía alemana en las personas de sus representantes Feuerbach, B. Bauer y Stirner, y del socialismo alemán en las de sus diferentes profetas. Barcelona: Grijalbo.

Matus, M. (2019). Desigualdad: la grieta que fractura la sociedad chilena. En Folchi, M. (Ed.), CHILE DESPERTÓ Lecturas desde la Historia del estallido social de octubre 2019 (pp. 59-68). Santiago: Universidad de Chile.

Mayol, A. (2012). El derrumbe del modelo: La crisis de la economía de mercado en el Chile contemporáneo. Santiago: LOM.

(2019). Big Bang. Estallido Social 2019. Modelo derrumbado, sociedad rota, política inútil. Santiago: Catalonia.

Milos Hurtado, P. (2007). Historia y memoria 2 de abril de 1957. Santiago: LOM.

Moulian, T. (1997). Chile actual: Anatomía de un mito. Santiago: LOM.

Palma, D. (2005). La "Revolución de la Chaucha". Santiago de Chile,16 y 17 de agosto de 1949. Alternativa, Revista Trimestral del Instituto de Ciencias Alejandro Lipschutz, 23, pp. 49-62.

Paredes, J. (2019). De la revolución pingüina a la arena de la gratuidad. Balance de 10 años de luchas estudiantiles en chile (2007-2017). En Díez García, R. \& Betancor Nuez, G. (Eds.). Movimientos sociales, acción colectiva y cambio social en perspectiva. Continuidades y cambios en el estudio de los movimientos sociales (pp. 133-147.) Abadiño: Fundación Betiko.

Paúl, F. (2019). Protestas en Chile: las 6 grandes deudas sociales por las que muchos chilenos dicen sentirse "abusados". BBC News Mundo 21 octubre 2019. Recuperado de https://www.bbc.com/mundo/ noticias-america-latina-50124583

Recabarren, L. E. (1905). La tierra y el hombre II. El Proletario Tocopilla, 4/abri1/1905. (pp. 141-142).

Repetto, A. (2016). Crecimiento, pobreza y desigualdad: la vía chilena. Economía y Política, 3(1), 71-101. DOI: 10.15691/07194714.2016.003.

Rodríguez, J. (2017). Desarrollo y desigualdad en Chile, 18502009. Santiago: Dirección de Bibliotecas, Archivos y Museos.

Rolnik, S. \& Guattari, F. (2006). Micropolítica. Cartografias del deseo. Madrid: Traficantes de Sueños.

Romero, M. (1957). Las luchas de abril y la provincia de Valparaíso. Principios, ํㅡㄴ, (pp. 12-15). 
Scott, J. (1976). The Moral Economy of the Peasant. New Haven: Yale University Press.

(2004). Los dominados y el arte de la resistencia. Discursos ocultos. México D.F.: Ediciones Era.

Tironi, E. (1988). Los silencios de la revolución. Chile: la otra cara de la modernización. Santiago: Ediciones SUR/Editorial La Puerta Abierta.
(1999). La irrupción de las masas y el malestar de las elites. Chile en el cambio de siglo. Santiago: Grijalbo.

Urteaga, E. (2009). Orígenes e inicios de los estudios culturales. Gazeta de Antropología, 25(1). Recuperado de http://hdl.handle. net/10481/6872 [4/7/2020].

Thompson, E. (1995). La formación de la clase obrera en Inglaterra. Barcelona: Crítica. 